\title{
«СКВОЗНЫЕ» ТЕХНОЛОГИИ В СОВРЕМЕННОМ МУЗЕЙНО-ВЫСТАВОЧНОМ ПРОСТРАНСТВЕ
}

\section{«END-TO-END» TECHNOLOGIES IN MODERN MUSEUM AND EXHIBITION SPACE}

N. Yurov

Summary. The article is devoted to the use of digital technologies, representatives of the economic community, called "through," in the modern museum and exhibition space. The author identifies their role in the formulation of a new modern cultural product. We consider the experience of applying artificial intelligence, robotics, virtual reality technologies and wireless communication as "radical innovations" successfully applied by famous artists around the world in order to create a new aesthetic experience. It is concluded that today there is a need to search for and develop new paradigm foundations and theoretical and methodological constructions that can detail and explain the proposal of works of modern digital art to reach the multisensory, bodily and affective levels of image generation and its perception by the viewer through the prism of generative partisan art.

Keywords: «end-to-end» technologies, museum and exhibition space, cultural product, creative and adversarial network, artificial intelligence, virtual reality.

\author{
Юров Никита Олегович \\ ФГОАУ ВО «Самарский национальный \\ исследовательский университет имени академика \\ С.П. Королева» \\ no.yurov@gmail.com
}

Аннотация. Статья посвящена вопросам применения digital-технологий, представителями экономического сообщества, названных «сквозными», в современном музейно-выставочном пространстве. Автором обозначена их роль в формулировании нового современного культурного продукта. Рассматривается опыт применения искусственного интеллекта, робототехники, технологий виртуальной реальности и беспроводной связи как «радикальных инноваций», успешно применяемых известнейшими художниками во всем мире в целях создания нового эстетического опыта. Делается вывод о том, что на сегодняшний день существует необходимость поиска и разработки новых парадигмальных основ и теоретико-методологических конструкций, способных детализировать и объяснить предложение произведений современного digital-искусства выхода на мультисенсорный, телесный и аффективный уровни генерации образа и его воспринятия зрителем через призму генеративного партиспаторного искусства.

Ключевые слова: «сквозные» технологии, музейно-выставочное пространство, культурный продукт, креативно-состязательная сеть, искусственный интеллект, виртуальная реальность.

тельной ситуации, вызванной становлением и развитием такого явления как креативная экономика (экономика эмоций) Данная концепция отражает специфическую систему взаимодействия между культурой, экономикой и технологиями, которая позволила креативным индустриям быстро стать глобальными, «и без труда пересекать национальные границы и завоевывать международные рынки» [4]. Фактически, именно эта транзитная способность отрасли и является одним из условий ее развития и роста. Следовательно, если digital-индустрия является катализатором роста креативной экономики (экономики эмоций), то концептуальный и материальный состав (структура) первой должен постоянно развиваться в целях популяризации получаемого в ходе этого «сотрудничества» культурного продукта.

Данный тезис доказывается тем фактом, что в музейно-выставочном пространстве всего мира актуализируется применение «сквозных» технологий и, более того, на экспериментальной базе формулируется опыт апробации действительно новых технико-технологических достижений. В данном контексте, вслед за Г.В. Су- 
ровицкой, «сквозные» технологии следует принимать как радикальные инновации [3], которые способствуют развитию не только конкретно экономических институтов, но и «околоэкономических», таких как искусство, коммерциализация которого все же второстепенна. Этот вопрос развит в работах Дж. Белла, Ч. Гира, М. Дакоса, М. Кастельса, Т. Куна, Н. Лумана, Дж. Нейсбита, Р.Б. Фуллера, Г. Хакена и пр.

Примером интеграции искусственного интеллекта в практику культурных институтов является совместный проект Эрмитажа и Российского фонда прямых инвестиций (2019), в рамках которого была создана выставка, представляющая 14 работ из 12 стран. Для их создания было использовано два основных механизма: первый - генеративно-состязательная сеть (GAN), созданная исследователем Я. Гудфеллоу в 2014 г. Это комбинация двух нейронных сетей с разным функционалом: одна все время создает максимально разные образцы на основе загруженной в нее информации, а вторая, состязательная,- дискриминатор, который отличает подражательные изображения, созданные первой сетью, от настоящих. Второй механизм - креативно-состязательная сеть (CAN). Она работает по тому же принципу создания и отбраковки, только дискриминатор осуществляет попытку соотнесения созданных работ с имеющимися в его базе данных стилями и направлениями. Благодаря этому взаимодействию генератор учится создавать работы, которые не совпадают ни с одним из стилей, известных дискриминатору. Одной из наиболее популярных картин стала работа итальянского художника Давиде Квайолы «Летние сады». Он отснял на видео цветы, которые колебались при порывах ветра. Далее работать стал не художник, а креативно-состязательная сеть - она преобразует полученную информацию в полотна французских импрессионистов. Одновременно с этим, палитра и движения на видео остаются неизменными: сеть создает поверх исходных данных новую живопись [1].

Наиболее ярким представителем «сквозной», или так называемой динамической живописи является канадский художник С. Басе. Он использует широкий спектр техник, основанных на привычных стилях живописи. Благодаря им, художник преобразовывает мазки кистью в алгоритмы, которые отображают так называемый «ДНК» картины (подобно ДНК живых организмов). Объекты, составляющие изображение, постепенно трансформируются, непрерывно меняют цвета и структуру поверхности. Одновременно с этим, картины всегда уникальны и никогда не повторяются. Процесс преобразования протекает плавно, создавая ощущение «текучести» составляющих элементов. Среди арт-проектов С. Басе - «Виртуальный пейзаж. Северная Канада», «Путешествие по фрактальному лесу», «Солярис», «Город» и др. В рамках данного «направления» искусства работала художница и био-хакера Х. Дьюи-Хагборг, которая в 2014 г. прошлась по улицам Нью-Йорка и собрала материалы, на которых могли остаться следы человеческого ДНК (окурки сигарет, использованная жевательная резинка), отнесла их в лабораторию и воссоздала портреты незнакомцев по их биологическому материалу с применением технологии роботизированной микроскопии. По сути, художница подняла вопрос о границах личного отдельно взятого человека.

Технологии беспроводной связи также становятся инструментом создания культурного продукта в современном музейно-выставочном пространстве. Под ними традиционно понимается «подкласс информационных технологий, которые служат для передачи информации на расстоянии между двумя и более точками, не требуя связи их проводами. Для получения информации может использовать инфракрасное излучение, радиоволны, оптическое и лазерное излучение» [2]. Классическими примерами таких технологий являются Bluetooth, WiFi и WiMax, беспроводные сенсорные сети, мобильные связи разных поколений $G$, спутниковые связи и другие. В разрезе искусства, интерактивные инсталляции студии «Stain» — «MIMPI» и «One Story» — как нельзя лучше иллюстрируют данную категорию. Первая представляет собой экспериментальный проект, стартовавший в 2012 г., который объединяет в себе многопользовательскую интерактивность и создание изображений. Зрители могут непосредственно влиять на создаваемое изображение, наклоняя свои мобильные устройства (на базе iOS или Android). Звуковое сопровождение для инсталляции создано музыкантом Lazyfish. Звук синхронизируется с изображением в реальном времени с помощью параметров vvvv через OSC. Взаимодействие публики с инсталляцией превращается в некую игру или, точнее, медитацию. Визуальная сложность изображения является метафорой виртуальных структур: какими бы сложными они не казались в целом - каждый человек в отдельности может очень легко изменять их части. Сознание каждого, кто участвует в этой инсталляции, полностью погружается в процесс изменения изображения и восприятие эмоционального ответа от этого процесса. Графически инсталляция выполнена в футуристическом стиле. Она содержит историческую иронию и желание переосмыслить наше отношение к технологиям. Потоки данных от зрителей трансформируют и окрашивают параметризованную поверхность изображения. Четвертым измерением в инсталляции является время. Его течение определяется тем, как зрители передвигают свои устройства - быстро или медленно, плавно или рывками. Погруженность В процесс непрерывного изменения изображения дополняется бодрой и мелодичной музыкой, меняющейся в зависимости от параметров изображения. 
Метод взаимодействия с инсталляцией для зрителей является весьма актуальным, что позволяет привлечь множество участников и обеспечивает богатый набор создаваемых образов. В контексте данной инсталляции наиболее справедлива одна из описанных Т. Шехтер трактовок времени в искусстве XX в.: время «как вечность, в которой не пребывают, но которая открывается и которая противостоит напряженному «зигзагообразному» времени человеческой жизни» [6].

Практика интеграции достижений виртуальной реальности в культурных институтах в значительной степени более развита, чем иные вариации «сквозных» технологий. В своей книге «From Technological to Virtual Art», Ф. Поппер исследует эволюцию интерактивного искусства в разрезе новых медиа и IT-инженерии, его отличия от своих исторических предшественников через современное компьютерное искусство, мультимедиа и netарт. Ученый показывает, что современное виртуальное искусство является собой дальнейшее совершенствование технологического искусства конца XX в., и, одновременно с этим, отход от него [8]. По мнению И.И. Югай, изучавшей в своих трудах проблематику медиареальности в изобразительном искусстве, опыт взаимодействия с ней позволяет digital-художникам расширять палитру выразительных средств, апробировать новые способы и принципы формообразования, поставить новые творчески задачи. При этом, формулируется особый партисипативный контекст, в основе которого лежат следующие основные задачи [7]:

- трансформация способов и форм деятельности, в т.ч. актуализация характерных для медиа структурных композиционных решений, причинно-следственных связей;

- смешение фигуративного и нефигуративного подходов;

- формулировка новой процессуальности, основанной на принципах работы с пользовательским интерфейсом;

- образность, заимствованная из новых медиа жанров;

- сочетание художественного и документального;

- увеличение или избыток визуальной информации.
Данные принципы в той или иной мере концентрируются в системе виртуального искусства как вида digital-искусства, созданного посредством «сквозных» технологий. В качестве актуальных примеров можно привести деятельность австрийского художника С. Кэмпбелла, известного под псевдонимом Sutu, который создает необычные трехмерные картины. По его словам, VR - это идеальная среда, обеспечивающая полноценное погружение зрителя в мир искусства. Разработчик игр из США К. Каули, воссоздал знаменитую картину В. ван Гога «Ночное кафе» в 3D, привнеся в нее дополнительные элементы. Зрители здесь, соответственно, не только пассивные наблюдатели, но и активные участники действия: программист добавил возможность побродить по нарисованному кафе с помощью контроллеров. Художник К. Мак создает красочные абстрактные композиции в виртуальной реальности, например, проект «Blortasia»: он называет свое искусство «The Mysterious Mystery of The Mystery of The Mysterious». В целом, отличительная черта VR-живописи - это чаще всего трехмерность изображения, анимация, а также дополнительные эффекты, например, музыкальный ряд, помогающий в большей степени эстетизировать как объект искусства, так и «территорию», на которой он находится.

Приведенные выше примеры наглядно иллюстрируют, как в рамках музейно-выставочного пространства произведения искусства создаются посредством digital «сквозного» инструментария. Безусловно, подобная практика отражает иной взгляд на культурный продукт в целом, однако, неоспоримо, что интерес и сложность исследования диджитализации изобразительного искусства в контексте техно-, или скорее инженерно-художественной гибридизации проистекают из скорости развития digital-технологий, существующих на стыке традиционного, т.е. доцифрового и постцифрового. Данный тезис обуславливает необходимость нового поиска и разработки новых парадигмальных основ и теоретико-методологических конструкций, способных детализировать и объяснить предложение произведений современного digital-искусства выхода на мультисенсорный, телесный и аффективный уровни генерации образа и его воспринятия зрителем через призму генеративного партиспаторного искусства.

\section{ЛИТЕРАТУРА}

1. Какое искусство создает искусственный интеллект. - 12.06.2019 // Электронное периодическое издание «Ведомости» (Vedomosti). — ULR: https://www. vedomosti.ru/lifestyle/articles/2019/06/12/804071-iskusstvo-sozdaet (дата обращения: 11.07.2020)

2. Колыбельников А. И. Обзор технологий беспроводных сетей // Труды МФТИ. 2012. Т. 4. № 2. С. 3-29

3. Суровицкая Г.В. «Сквозные» цифровые технологии в региональной экономике // Модели, системы, сети в экономике, технике, природе и обществе. 2019. № 4 (32). C. 16-23.

4. Чепьюк О.Р., Кравченко В.С., Демина М.Г. От креативной экономики к эстетическому капитализму: к вопросу о роли эмоций в экономической коммуникации // Философия хозяйства. 2018. № 4. С. 70-82 
5. Что такое цифровая экономика? Тренды, компетенции, измерение: докл. кXX Апр. междунар. науч. конф. по проблемам развития экономики и общества, Москва, 9-12 апр. 2019 г. / Г. И. Абдрахманова, К. О. Вишневский, Л. М. Гохберг и др.; науч. ред. Л. М. Гохберг; Нац. исслед. ун-т «Высшая школа экономики».—- М.: Изд. дом Высшей школы экономики, 2019.- 82 с.

6. Шехтер Т. Е. Искусство как образ мира: Избранные работы по теории и истории искусства. — СПб.: СПбГУП, 2012. — 390 с.

7. Югай И. И. Медиа реальность в изобразительном искусстве // Наука телевидения. 2019. № 15.2. С. 183-205

8. Popper F. From technological to virtual art. — Cambridge, Mass; London: MIT press, cop. 2007. — 459 p.

(c) Юров Никита Олегович ( no.yurov@gmail.com ).

Журнал «Современная наука: актуальные проблемы теории и практики»

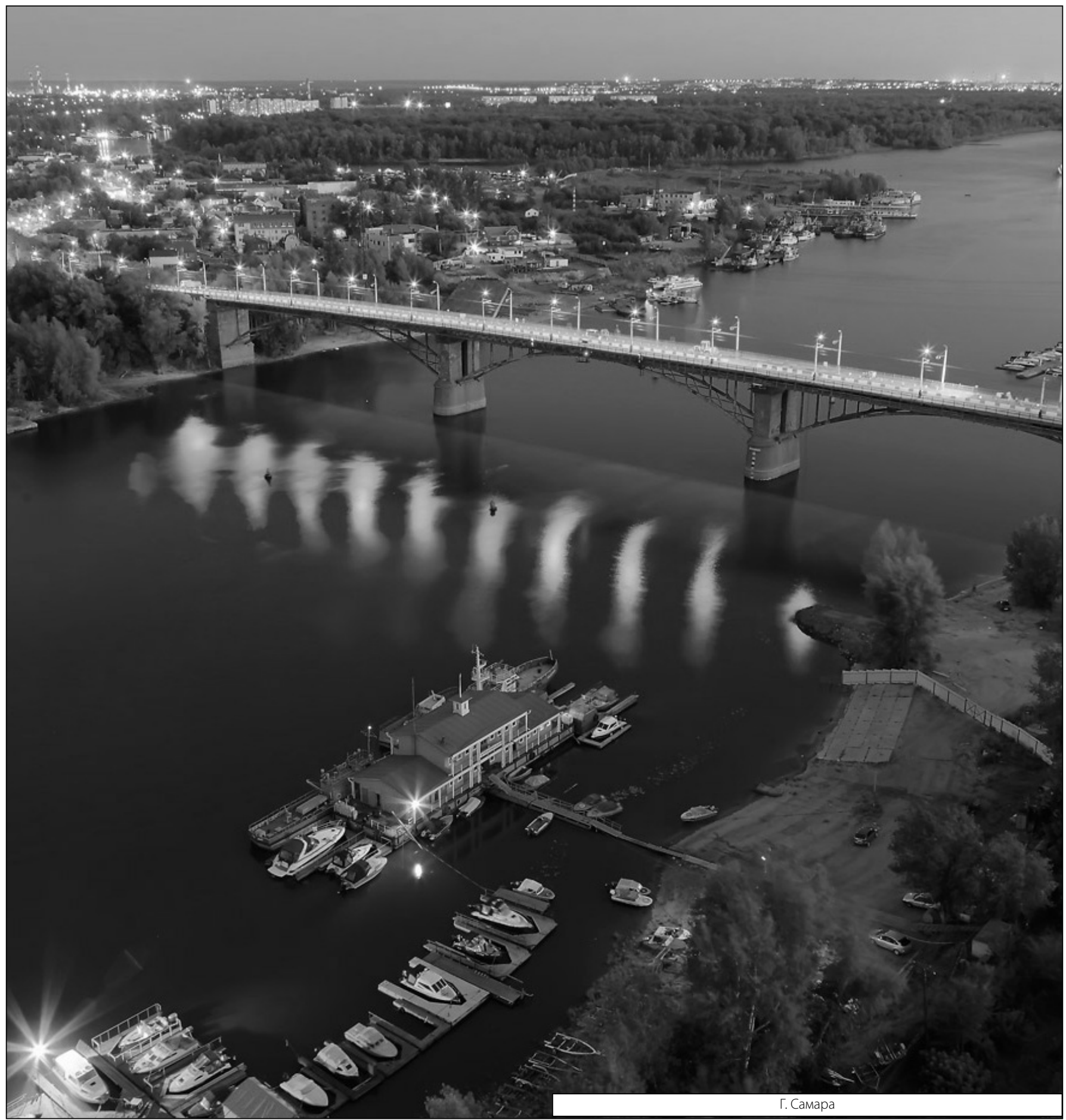

